\title{
LA SOFRA (SUJRA) EN EL SHARQ AL-ANDALUS ANTES DE LA CONOUISTA CATALANO-ARAGONESA
}

\author{
Por \\ MIKEL DE EPALZA \\ $\checkmark$ MARIA JESÜS RUBIERA
}

A R. I. Burns, con motivo de su investidura como Doctor Honoris Causa por la Universidad de Valencia

La sofra es una carga en forma de prestación personal o de trabajo forzado que recae sobre las comunidades mudéjares bajo el dominio de la Corona de Aragón, pasando más tarde a los moriscos. El primer estudio importante fue el realizado por M. Gual Camarena (1), pero quien ha definido el origen y desarrollo de dicha carga ha sido R. I. Burns (2). El profesor norteamericano determinó en primer lugar que la sofra aparecía ya en el siglo XIII, frente a la opinión de Gual Camarena que creía que su aparición databa del siglo XIV, y que, dada esta aparición temprana, junto a la existencia de esta institución en el Oriente Islámico, podía suponerse que la sofra era de origen islámico, hipótesis reforzada por ser la palabra sofra -en castellano azofraun arabismo, procedente del étimo árabe sujra: "trabajo penoso o forzado" (3).

La sofra aparece en el siglo XIII especialmente como servitutem castrorum, consistente en acarrear al castillo, con bestias o sin ellas, principalmente agua y leña, u otra clase de "pertrechos" (4), quedando sin embargo diferenciados de la sofra, la entrega de los productos agrícolas $(5)$. Posiblemente entrase en la sofra como servicio al castillo también la construcción o reparación de murallas, torres, etc. (6).

El profesor Burns hace notar también la frecuencia con la que la obligación de la sofra aparece acompañada con el pago de aves de corral y que ambas cosas, trabajo forzado y aves, podian ser compensadas por el pago de un impuesto en metálico (7), circunstancia que puede tener su explicación, como veremos, en la especificidad de la sujra en época islámica.

(1) "Los mudéjares valencianos: aportaciones para su estudion, Saitabi, 7 119491. p. 181.

(2) Medieval Colonialism. Postcrusade Explotation of Islamic Valencia, Princenton University Press, 1975, pp. $162-179$.

(3) R. Dozy y W. H. Engelmann, Glossaire des mots espagnais et portugais dérivés de /'arabe, Leiden, 1965 (r), pp. $227-228$.

(4) Burns, op. cit. . p. 163.

(5) Burns, op. cit., p. 170

(6) Burns, op. cit., o. 171.

(7) Burns, op. cit, pp. 160-161 
P. Guichard (8) trató más tarde de la sofra en un artículo que pretende ser una contestación a R. I. Burns, al que acusa de continuista y optimista. Comienza por afirmar que la suira sería rara en época islámica porque «ni le concept égalitaire de la communauté des croyants, ni les structures socio-économiques qui excluent généralement la seigneurie banale ou foncière au sens occidental du terme, ne se prêtent facilement à son apparition ou à sa diffusion” (9), con lo que demuestra que gana ampliamente al posible optimismo de Burns en lo que a las instituciones islámicas se refiere. Abunda en su improbable carácter islámico apoyándose en el rechazo que a dicha carga ofrecen las comunidades mudéjares de Ascó, el Bajo Ebro y especialmente la de Aldea de Tortosa. Sin embargo, en uno de los sorprendentes giros dialécticos del esforzado investigador francés, termina llegando a las mismas conclusiones que Burns: la sofra tiene su origen en época islámica, aunque seria una carga estatal, mientras que para los cristianos es una carga señorial

Dado este estado de la cuestión creemos interesante presentar aquí un texto andalusí que se refiere al siglo XII y al Sharq al-Andalus, en el que aparece la sujra perfectamente descrita. El texto nos ha sido transmitido por Ibn al-Jațib (10), y su autor es un "historiador digno de crédito», del círculo de Abū yáffar al-Waqqāshi.

Este personaje, estudiado por Elías Terés (11), era gobernador de Jaén en nombre de Ibn Hamushko, aliado y suegro de Ibn Mardanish, el rey "Lobo". Cuando aquél se pasó a los almohades en 1169, su yerno, Ibn Mardanish, atacó Jaén y además confiscó todas las propiedades de los leales de lbn Hamushko, entre ellas un molino que tenía $A b \bar{u} \hat{y} a^{c} f a r$ al-Waqqāshi en la Walâya de Valencia, lo que motivó que el gobernador de Jaén escribiese un encolerizado poema contra Ibn Mardanish. En este contexto se sitúa el relato que ofrecemos. El narrador, que era un excelente literato, acumula sobre un personaje imaginario, un tal lbn Abd Allah de Xátiva, todas las desgracias fiscales que le podian sobrevenir a un súbdito de Ibn Mardanish, con lo que tenemos una vivísima relación de los impuestos y cargas del reino de lbn Mardanish, que como podemos recordar abarcaba un territorio que iba desde Castellón a Murcia. El relato es el siguiente:

"Dice uno de los historiadores dignos de crédito: Estaba yo en Jaén con el ministro Abū ýa far al-Waqqāshi y llegó un hombre de Murcia al que conocía y le preguntó cómo iban los asuntos de Ibn Mardanish, y el hombre dijo: "Te informaré de la opresión e injusticia de sus gobernadores" y contó la historia siguiente:

"Un súbdito (de Ibn Mardanish), que era de Játiva y se llamaba Muhàmmad lbn Abd Allah, tenía en los alrededores de esta ciudad una pequeña finca de la que vivía, pero los impuestos superaron sus ganancias y huyó a Murcia, aunque lbn Mardanish tenía establecido que quien huyese ante el enemigo (12), se le confiscarían los bienes para el tesoro. El hombre de Xátiva contaba:

"Cuando llegué a Murcia, huido de mi patria, me coloqué en la construcción y llegué a reunir dos mithqales de oro; un día, al pasar por el zoco, me encontré con unos parientes míos de Xátiva y les pregunté por mis hijos y por mi mujer; me dijeron que estaban bien y me llené de alegría; también les pregunté por mi finquita y me dijeron que estaba en poder de mis hijos, por lo que les invité a celebrarlo aquella noche en mi casa. Compré carne y bebidas, y pasamos la noche tocando el adufe.

\footnotetext{
(8) "Le problème de la sofra dans le royaume de Valence au XIIle siècle", Awrăq, 2 (1979), pp. 64-71.

(9) Guichard, op. cit., p. 66

110 Ihàta. Ed. Inăn, El Cairo, 1974, II, pp. 124-126.

111 "Textos poéticos árabes sobre Valencia”, Al-Andalus, XXX 11965), pp. 302-303

(12) Este texto podría interpretarse como que el que huía del trabajo de la tierra, y por tanto de pagar los impuestos que servian para pagar el ejército, perdia sus tierras.
} 
Al amanecer llamaron con fuerzo a la puerta y cuando pregunté quién era, me contestaron: "Soy el recaudador encargado de las alcábalas de las fiestas: debes pagar. porque ayer tocasteis el adufe; dame el canon de las bodas que habéis celebrado". Yo le dije que no habíamos celebrado ninguna boda, pero no me hizo caso y me llevó a la cárcel, de donde no me soltó hasta que hube pagado un mithqal de los que había ganado.

"Al volver a mi casa me dijeron que había llegado Fulano, de Xátiva, en aquel momento; fui a preguntarle por mis hijos y me dijo que estaban en la cárcel y que mi finquita se encontraba en el registro de las tierras montaraces (13). Volví a mi casa con mis parientes y les conté lo que había pasado, y pasamos la noche llorando. A la mañana siguiente llamaron a la puerta. Salí a ver quién era y me encontré con el encargado de las herencias, que me dijo que le habían informado de que habiamos pasado la noche llorando, y que por tanto alguien se nos había muerto y que heredaríamos. Yo le dije que no lloraba sino por mí mismo, pero no me hizo caso y me llevó a la cárcel; le entregué el mithqal que me quedaba y volvi a mi casa.

"Después me dirigí al río, a la Puerta del Puente, para lavarme la ropa que estaba sucia de la cárcel; crucé el río y se la di a una mujer que lavaba la ropa, despojándome de ella; la mujer me dio una capa rústica (zunnär) para que me cubriera. Y he aqui que en ese momento pasaba el eunuco del alcaide de Ibn Mardanish, que conducia a setenta montañeses (ahl al-yaball, vestidos con capas rústicas, y al verme de la misma forma vestido, ordenó que me llevasen al trabajo forzado (ilàs-sujrá) y al servicio en el Castillo de Monteagudo (14), durante diez días, y allí estuve sirviendo y presente durante los diez dias, aunque lloraba y me quejaba al alcaide, hasta que tuvo compasión de mí y me soltó.

"Volví en dirección a Murcia y en la puerta de la ciudad, me preguntaron cuál era mi nombre y contesté que Muhàmmad ibn Abd Allah de Xátiva; el policía me cogió y me llevó al recaudador de la Puerta del Puente, y le dijeron: "'Éste es uno de los inscritos como dueño de tales joyas y tales dinares". Yo dije: "Soy sólo un hombre de Xátiva; mi nombre debe coincidir con ese otro nombre", y le conté lo que me había pasado; se compadeció de mí entre risas y me soltó. Entonces hui y me vine aquí."

De esta descripción de desgracias del contribuyente andalusí del siglo XII, hemos destacado el párrafo en el que se describe la sujra, como servitutem castrorum, es decir, como la sofra del siglo XIII. En el caso de que se trate de el Hișn Montagũt, como creemos, la sofra de este relato sería de acarreo de agua, leña u otros pertrechos; en el caso de tratarse de un castillo derribado, en la versión del editor 'Inān, nos encontraríamos con una sofra de reconstrucción de su fábrica. En ambos casos este texto nos ofrece el antecedente musulmán y sharquí de la carga utilizada por los conquistadores sobre sus súbditos musulmanes y con sus mismas características: un servicio obligatorio y relacionado con el castillo, y además ejercido por un alcaide, que ejerce un derecho real, indudablemente delegado por el Rey Lobo. Y no vemos en este sentido una gran diferencia con la sofra impuesta por los alcaides cristianos, en los que el rey de Aragón delega los derechos reales, en los señores como el propio P. Guichard reconoce (15), tanto más cuando la sofra se halla vinculada en época aragonesa también a los castillos y no a las zonas agrícolas o señoríos de producción.

\footnotetext{
(13) Traducción conjetural de rasmu i-ỳabåa.

(14) El editor del texlo M. Inan lee hişn masqüt, "castillo dersibado o caido", pero creemos que es hisn muntaqũt, "castillo de Monteagudon, cerca de Murcia.

(15) Guichard, op. cit., p. 69 .
} 
Pero la importancia de este texto no se agota al mostrar un antecedente directo islámico de la sofra de época cristiana: la sujra aparece vinculada directamente a un grupo económico social: los montañeses - ahl al-yabal-ya que al protagonista del relato - pequeño propietario agrícola transformado en obrero ciudadano - le reclutan para la sujra porque va vestido de montañés, como los setenta hombres que conduce el eunuco del alcaide. Este grupo socioeconómico de gentes de la montaña podría ser un tercer elemento de la dicotomía va conocida en la sociedad arabigoislámica de Al-Andalus: ciudad/campo; ciudadanos/campesinos. Éstos pagan sus impuestos que en ambos casos consistirían en una parte de su producción, ya sea de la industria, el comercio, la agricultura o la ganadería. En este contexto de oposiciones podríamos pensar que la sujra sería una carga sustitutoria que recaía en los montañeses, ya que éstos no producían nada - estamos hablando de la montaña mediterránea, no de los montes de bosque boreal - y no podían pagar el jarăy̆ o impuesto sobre la producción de la tierra.

La única riqueza de los montañeses son los brazos de sus hombres, y pagan sus impuestos con trabajo en las obras públicas (los castillos son unas importantes obras públicas militares). En texto de Ibn al-Jatib nos menciona incluso la duración de este trabajo forzado - diez días-, pero parece que se trata de montañeses llevados a la llanura para que sirvan a un castillo ciudadano. Cabe pensar que los castillos enclavados en las montañas tendrían un servicio de sujra habitual de los habitantes de la zona, tal y como aparecen en las fuentes cristianas, en las que está establecido el día de servicio. La especifidad de la sujra referida a los montañeses ilumina la historia de la sofra bajo dominio aragonés, ya que los lugares que aparecen en el siglo XIII sujetos a la carga de la sofra pertenecen a las zonas montañosas del País Valenciano y nunca a las llanuras:Chivert, Eslida, Uxo, Alfandech, Chulilla, Confrides, Gallinera, Alcalá de la Jovada, Luchente, Montaberner, Serra, Torres Torres, Vallada, Segarria, Vall de Laguart, Pop, Jalón, Calpe, Olocaiba, Polop y Denia, que están en su mayor parte en la "Montaña» de Alicante, $y$ están ausentes de sofra los lugares pertenecientes por ejemplo a la Huerta de Valencia o a la Ribera del Júcar, que sin ninguna duda eran agrícolas.

Si la sofra es un impuesto sustitutorio para regiones que hoy llamariamos «deprimidas", sin agricultura, tendría sentido la entrega de aves de corral junto al servicio de la sofra, como tal vez los únicos animales que producían las gentes de la montaña.

La resistencia que el protagonista del relato muestra ante su reclutamiento para la sujra es también paradigmática y podría ponerse en relación con la misma resistencia ofrecida por las aljamas mencionadas por $P$. Guichard en el valie del Ebro ante la imposición de la sofra. El protagonista del relato y estas aljamas tienen algo en común: no son montañeses y les imponen una carga que no les afecta, ya que son agricultores y ciudadanos, y como tales, sujetos a impuestos en especie o en metálico sobre su producción. Su rechazo no es, como quiere P. Guichard, porque la sofra sea ajena a su propia tradición musulmana (16), sino porque no les correspondía según su propio estatuto económicosocial: eran agricultores y no montañeses. Como tales, tendrían también trabajos agrícolas forzados que recibían nombres latinos como venema (deformación de vendimia), colonias o simplemente servicios (17), que no son confundibles con la sofra, como distingue Burns, y que afectaban también a los

\footnotetext{
(16) Guichard, op. cit., p. 66

(17) Burns, op. cit., p. 169 .
} 
agricultores cristianos, mientras la sofra afectaba sólo a los mudéjares. La imposición de la sofra a comunidades mudéjares agrícolas es uno más de los errores de los conquistadores, que no comprenden la realidad islámica, al generalizar una carga que estaba reservada a un grupo socioeconómico, los montañeses - el carácter igualatorio de la sociedad islámiça, según P. Guichard, está por demostrar-. Este fenómeno de incomprensión institucional ha sido señalado por R. I. Burns en esta misma revista, intentando superar los etiquetismos fáciles: "La distorsión de muchas instituciones o estructuras fue especialmente radical en los elementos que servían de eslabón entre la sociedad de los conquistados y de los conquistadores - los que representaban características análogas - de modo que el conquistador las interpretaba erróneamente y las moldeaba de acuerdo con su propia experiencian (18).

(18) "L.os mudéjares de la Valencia de las Cruzadas: un capitulo olvidado de la Historia islámican, Sharq al-Andalus, 1 (1984). p. 18. 